\section{HLA class II genes in primary sclerosing cholangitis and chronic inflammatory bowel disease: no HLA-DRw52a association in Swedish patients with sclerosing cholangitis}

\author{
H Zetterquist, U Broomé, K Einarsson, O Olerup
}

\begin{abstract}
The familial predisposition to chronic inflammatory bowel disease and the increased concordance rate in monozygotic twins with Crohn's disease, suggest that genetic factors influence disease susceptibility. A $100 \%$ association with the supertypic HLA class II specificity DRw52a was recently described in white North American patients with primary sclerosing cholangitis, with or without concurrent ulcerative colitis. ${ }^{1}$ HLA class II alleles of the DR, DQ, and DP subregions were determined by genomic typing techniques in a large group of Swedish patients with ulcerative colitis or Crohn's disease as well as in a series of patients with primary sclerosing cholangitis. No statistically significant HLA class II association was observed in any of the investigated diseases or when the patients were subgrouped according to disease site or occurrence of extraintestinal manifestations, except an insignificant increase of the DRw17, DQw2 haplotype in patients with primary sclerosing cholangitis. The failure to confirm the well established DRw17 association in Swedish patients with sclerosing cholangitis probably represents a statistical type II error. Furthermore, this study did not verify the recently described strong $\mathrm{DRw} 52 \mathrm{a}$ association in sclerosing cholangitis $-52 \%$ of the patients were DRw52a positive compared with $28 \%$ of the controls $\left(p<0.05, p_{c}\right.$ NS). This discrepancy was probably caused by different typing techniques. The DRw52a specificity was determined directly by hybridising HLA-DRB3 genes, group specifically amplified by the polymerase chain reaction, with an allele specific oligonucleotide probe, whereas in the previously mentioned study DRw52a was assigned by indirect serological criteria, which overestimate the frequency of this allele.
\end{abstract} NOVUM, Huddinge and Departments of Clinical Immunology and Medicine, Karolinska Institute at Huddinge Hospital, Huddinge, Sweden.

H Zetterquist

U Broomé

K Einarsson

O Olerup

Correspondence to:

Dr O Olerup,

Center for BioTechnology,

Karolinska Institute,

NOVUM, S-141 57

Huddinge, Sweden.

Accepted for publication

4 November 1991

Many diseases with a suspected autoimmune aetiology or pathogenesis, or both, have been found to be associated with alleles of the human leukocyte antigen (HLA) class II region. With the introduction of genomic typing techniques a few of the HLA associated diseases have been found to be related to specific amino acids or epitopes of the polymorphic membrane distal domains of the class II molecules - for example insulin dependent diabetes mellitus, ${ }^{2}$ rheumatoid arthritis, ${ }^{3}$ and selective immunoglobulin A
Karolinska Institute, deficiency. ${ }^{+}$Only two of the HLA associated diseases show a close to $100 \%$ association with a specific class I or II allele, ankylosing spondylitis with HLA-B $27^{56}$ and cataleptic narcolepsy with HLA-DR2. ${ }^{78}$ It was recently suggested that primary sclerosing cholangitis might be added to the list of diseases having a $100 \%$ association with an HLA allele - DRw52a. ${ }^{\prime}$ Furthermore, specific amino acid positions of the DRw52a $\beta$ chain were suggested to determine the susceptibility to sclerosing cholangitis.

The racial and ethnic differences in the prevalence of ulcerative colitis and Crohn's disease, as well as the familial predisposition to chronic inflammatory bowel disease, suggest that disease susceptibility is influenced by genetic factors. In a large Swedish population based twin study an increased concordance rate in monozygotic compared with dizygotic twins was observed in Crohn's disease, which further supports the view that genetic factors are of aetiological importance. ${ }^{9}$

In recent years, serological, cellular, and biochemical tissue typing methods have been at least partially replaced by indirect (restriction fragment length polymorphism analysis RFLP) and direct (hybridising DNA amplified by the polymerase chain reaction with sequence specific oligonucleotide probes - PCR-SSO and sequencing genomic techniques to detect allelic HLA polymorphism. RFLP analysis of HLA class II genes, especially DR and DQ, has been developed into a powerful tool for identifying allelic variability, with a close correlation between specific RFLPs and cellularly and serologically defined class II specificities. "11 However, the alleles of the DRw52 supertypic specificity cannot be directly determined by TaqI RFLP typing. Furthermore, the cellularly defined DR4 associated Dw specificities cannot be separated by unique RFLPs. These limitations of the RFLP method can be resolved by the PCR-SSO typing technique. $1:-1+$

The aims of the present study were three fold: group of Swedish patients with primary sclerosing cholangitis, using a genomic typing method directly identifying the DRw52a specificity; (ii) to investigate whether alleles of the HLA class II region were associated with susceptibility to ulcerative colitis or Crohn's disease in white people; and (iii) to look for HLA class II associations in patients subgrouped according to disease location and occurrence of extraintestinal manifestations. 


\section{Methods}

PATIENTS

Twenty one patients with primary sclerosing cholangitis, diagnosed by established biochemical, histological, and cholangiographic criteria, ${ }^{1516}$ were included in the study. Seven of the patients had end stage liver disease, defined as accepted for transplantation, transplanted, or deceased. Sixteen of the cholangitis patients had ulcerative colitis and two had Crohn's disease. In addition 73 patients with ulcerative colitis and 63 with Crohn's disease were investigated. The diagnosis of chronic inflammatory bowel disease was based on a typical history and characteristic endoscopic and radiological findings. ${ }^{1718}$ Fifty seven of the 89 patients with ulcerative colitis had pancolitis. In 26 patients, only the left part of the colon was affected. Colitis patients with disease confined to the rectum were excluded. In 10 of the 65 patients with Crohn's disease the small bowel only was affected and in 12 the disease was confined to the colon. Forty three patients had ileocolic Crohn's disease. Besides primary sclerosing cholangitis, eight of the patients with ulcerative colitis had extraintestinal disease manifestations - two sacroileitis, three arthritis, two iritis, and two pyoderma gangraenosum. Eleven of the patients with Crohn's disease had extraintestinal manifestations - two cholangitis, five sacroileitis, two arthritis, two iritis, and two pyoderma gangraenosum. All patients were from white north European families.

\section{CONTROLS}

Two hundred and fifty randomly selected, healthy Swedes were used as controls.

\section{SOUTHERN BLOT ANALYSIS}

DNA was extracted from peripheral blood leukocytes by phenol/chloroform extraction of proteinase-K treated nuclei. Restriction enzyme digests, agarose gel electrophoresis, capillary blotting of DNA fragments onto nylon membranes, labelling of purified probe inserts, hybridisation, stringency washes, and autoradiography were performed according to standard techniques with minor modifications as previously described. ${ }^{19}$

TaqI DRB, DQA, AND DQB RFLP TYPING

Allelic TaqI DRB, DQA, and DQB restriction fragment patterns were analysed as previously described. ${ }^{11}$ The serologically (DR and DQ) and cellularly defined (Dw) specificities associated with the different TaqI patterns are given in the text and Tables. ${ }^{1011}$

\section{MSPI DPA AND DPB RFLP TYPING}

Allelic MspI DPA and DPB restriction fragment patterns were analysed as previously described. ${ }^{20}$ The cellularly defined DP specificities associated with the different allelic MspI patterns are given in the text and Tables. ${ }^{20}$

\section{AMPLIFICATION OF DRB3 GENES}

The polymorphic second exon of DRB3 genes, encoding the DRw52a-DRw52c specificities, were group specifically PCR amplified as previously described, ${ }^{13}$ except that the general 3' DRB primer matched codons $78-84$, in all patients with primary sclerosing cholangitis and in 60 individuals representing the 10 white DRw52 associated TaqI DRB-DQA-DQB haplotypes.

\section{AMPLIFICATION OF DRB 1 GENES IN DR4}

\section{HAPLOTYPES}

The polymorphic second exon of DRB1 genes of the DR4 associated cellular specificities, Dw4, Dw10, Dw13, Dw14, and Dw15, were group specifically PCR amplified by nested PCR in all DR4 positive patients and 69 randomly selected DR4 positive controls. Initial group specific amplifications $^{14}$ were followed by a second amplification step with internal primers complementary to codons $39-45$ and $78-84$ for increased amplification efficiency.

HYBRIDISATION WITH OLIGONUCLEOTIDE PROBES PCR amplified product was dot blotted onto nylon membranes. $3^{\prime}$ end-labelling of synthetic oligonucleotide probes with ${ }^{32} \mathrm{P}$, prehybridisation, hybridisation and stringency washes were performed as previously described. ${ }^{21}$ The sequences of the DRw52 and DR4 SSOs used are given in references 13 and 14, respectively. Nine DRw52 positive and seven DR4 positive homozygous cell lines of the 10th International Histocompatibility Workshop were used as specificity controls.

\section{STATISTICAL ANALYSIS}

Data were analysed by the $\chi^{2}$ test or Fisher's exact test when appropriate. Probability values were corrected for the number of determined antigens as well as for subgrouping the patients according to disease location or the occurrence of extraintestinal manifestations $\left(p_{c}\right)$.

\section{Results}

PRIMARY SCLEROSING CHOLANGITIS

A statistically insignificant increase of the DRw17 allele was observed in patients with sclerosing cholangitis. The DRw52a frequency was almost twice as high in the patients $(52 \%)$ as in the controls $(28 \%)\left(p<0.05 ; p_{c}, N S\right)$, mostly because of an increase in the DRw17,DQw2, DRw52a haplotype. Insignificant decreases of DR4 ( $\left.<<0.05 ; \mathrm{p}_{\mathrm{c}}, \mathrm{NS}\right)$ and DRw53 (p<0.01; $p_{c}$, NS) were also seen (Table I).

An increase of the DR2 allele in DR3 negative patients was recently described in a large group of northern European patients with primary sclerosing cholangitis. ${ }^{22}$ In our relatively small series of patients we did not find a significant increase of DR2 in DR3 negative patients; $50 \%$ of 14 DR3 negative patients were DR2 positive compared with $34 \%$ of DR3 negative controls $\left(\mathrm{p}_{\mathrm{c}}, \mathrm{NS}\right)$. 
TABLE I Distributions (\%) of DR-DQ phenotypes, and DRw52, DRw53, and DP alleles in patients with primary sclerosing cholangitis (PSC); combined sclerosing cholangitis and ulcerative colitis $(P S C+U C)$; ulcerative colitis (UC) and Crohn's disease (CD) compared with healthy controls

\begin{tabular}{|c|c|c|c|c|c|c|}
\hline$D R$ & $D Q$ & $\begin{array}{l}P S C \\
(n=21)\end{array}$ & $\begin{array}{l}P S C+U C \\
(n=16)\end{array}$ & $\begin{array}{l}U C \\
(n=89)\end{array}$ & $\begin{array}{l}C D \\
(n=65)\end{array}$ & $\begin{array}{l}\text { Controls } \\
(n=250)\end{array}$ \\
\hline $\begin{array}{l}\text { 1, 'Br' } \\
\text { 'Br' } \\
4 \\
4 \\
7 \\
7 \\
\text { w8 } \\
9 \\
\text { w10 } \\
\text { w11 } \\
\text { w12 } \\
\text { w13 } \\
\text { w13 } \\
\text { w14 } \\
\text { w15 } \\
\text { w16 } \\
\text { w17 }\end{array}$ & $\begin{array}{l}\text { w5 } \\
\text { w7 } \\
\text { w7 } \\
\text { w8 } \\
\text { w2 } \\
\text { w9 } \\
\text { w4 } \\
\text { w9 } \\
\text { w5 } \\
\text { w7 } \\
\text { w7 } \\
\text { w6 } \\
\text { w7 } \\
\text { w5 } \\
\text { w6 } \\
\text { w5 } \\
\text { w2 }\end{array}$ & $\begin{array}{r}29 \\
0 \\
5 \\
10 \\
0 \\
0 \\
5 \\
0 \\
5 \\
5 \\
0 \\
38 \\
0 \\
0 \\
33 \\
0 \\
33\end{array}$ & $\begin{array}{r}19 \\
0 \\
6 \\
13 \\
0 \\
0 \\
6 \\
0 \\
6 \\
6 \\
0 \\
44 \\
0 \\
0 \\
31 \\
0 \\
31\end{array}$ & $\begin{array}{r}29 \\
1 \\
7 \\
12 \\
9 \\
2 \\
8 \\
1 \\
3 \\
6 \\
7 \\
34 \\
1 \\
3 \\
34 \\
1 \\
27\end{array}$ & $\begin{array}{r}22 \\
0 \\
11 \\
20 \\
12 \\
8 \\
14 \\
0 \\
3 \\
11 \\
3 \\
32 \\
0 \\
6 \\
22 \\
0 \\
23\end{array}$ & $\begin{array}{r}18 \\
0 \\
12 \\
26 \\
7 \\
5 \\
9 \\
4 \\
2 \\
14 \\
6 \\
29 \\
2 \\
6 \\
30 \\
1 \\
17\end{array}$ \\
\hline $\begin{array}{l}\text { DRw52a } \\
\text { DRw52b } \\
\text { DRw52c } \\
\text { DRw53 }\end{array}$ & $\begin{array}{l}- \\
- \\
-\end{array}$ & $\begin{array}{r}52 \\
19 \\
5 \\
14\end{array}$ & $\begin{array}{r}56 \\
19 \\
6 \\
19\end{array}$ & $\begin{array}{r}44 \\
28 \\
6 \\
31\end{array}$ & $\begin{array}{l}22 \\
32 \\
22 \\
49\end{array}$ & $\begin{array}{l}28 \\
32 \\
11 \\
48\end{array}$ \\
\hline$D P$ & & $\begin{array}{l}P S C^{\star} \\
(n=18)\end{array}$ & $\begin{array}{l}P S C+U C \\
(n=15)\end{array}$ & $\begin{array}{l}U C^{\star} \\
(n=86)\end{array}$ & $\begin{array}{l}C D^{\star} \\
(n=61)\end{array}$ & $\begin{array}{l}\text { Controls } \\
(n=250)\end{array}$ \\
\hline $\begin{array}{l}\text { w1 } \\
\text { w2 } \\
\text { w3/w6† } \\
\text { w4 } \\
\text { w5 } \\
\text { CDP-HEI }\end{array}$ & & $\begin{array}{r}17 \\
33 \\
33 \\
89 \\
0 \\
0\end{array}$ & $\begin{array}{r}20 \\
27 \\
33 \\
87 \\
0 \\
0\end{array}$ & $\begin{array}{r}8 \\
22 \\
44 \\
85 \\
1 \\
0\end{array}$ & $\begin{array}{r}10 \\
25 \\
44 \\
79 \\
3 \\
2\end{array}$ & $\begin{array}{r}8 \\
21 \\
36 \\
86 \\
6 \\
0\end{array}$ \\
\hline
\end{tabular}

« Three patients with primary sclerosing cholangitis, three patients with ulcerative colitis and four patients with Crohn's disease were not HLA-DP typed.

† DPw3 and DPw6 cannot be distinguished by RFLP analysis. ${ }^{20}$

There were no differences in the distributions of DR, DQ or DP alleles, or DR-DQ haplotypes in sclerosing cholangitis patients compared with patients with both cholangitis and ulcerative colitis (Table I). This was in contrast to the findings in white American patients in whom a stronger association with the extended A1,B8 Cw7,DRw17,DQw2,DRw52a haplotype was observed in patients with combined sclerosing cholangitis and ulcerative colitis than in patients with cholangitis without ulcerative colitis,' but in agreement with the observations in a large series of white northern European patients. ${ }^{22}$

\section{ULCERATIVE COLITIS}

In patients with ulcerative colitis, a statistically insignificant increase of the DRw17, DQw2 haplotype was observed $-27 \%$ of the patients compared with $17 \%$ of the controls (Table I) $\left(\mathrm{p}<0.05 ; \mathrm{p}_{\mathrm{c}}, \mathrm{NS}\right) . \mathrm{DR} 4$ and DRw53 were found to be insignificantly decreased $\left(p<0.005 ; p_{c}\right.$, NS and $\mathrm{p}<0.01 ; \mathrm{p}_{\mathrm{c}}, \mathrm{NS}$, respectively). The frequencies of all the other determined $\mathrm{DR}, \mathrm{DQ}$,

TABLE II Distribution (\%) of the DR4 associated cellular specificities, Dw4, Dw10, Dw13, Dw14 and Dw15, in patients with ulcerative colitis (UC) and Crohn's disease $(C D)$ compared with healthy controls

\begin{tabular}{lccc}
\hline $\begin{array}{l}\text { DR4 associated } \\
\text { cellular specificity }\end{array}$ & $\begin{array}{l}U C \\
(n=17)\end{array}$ & $\begin{array}{l}C D \\
(n=20)\end{array}$ & $\begin{array}{l}\text { Controls } \\
(n=69)^{\star}\end{array}$ \\
\hline Dw4 & 65 & 65 & 70 \\
Dw10 & 0 & 0 & 1 \\
Dw13 & 0 & 20 & 3 \\
Dw14 & 35 & 20 & 26 \\
Dw15 & 0 & 5 & 4 \\
\hline
\end{tabular}

^ Fourteen of the DR4 positive controls were not DR4 subtyped.

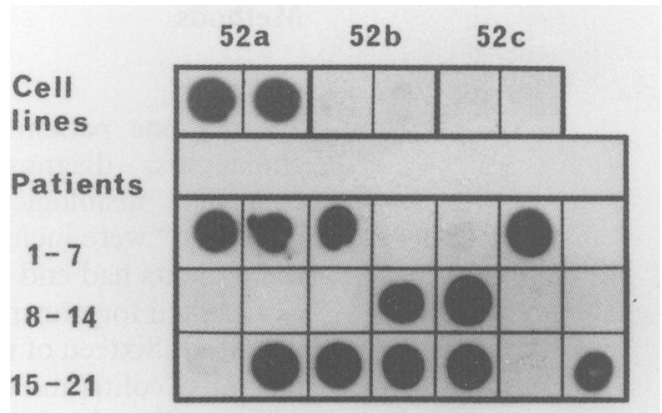

Dot blot of group specifically PCR amplified HLA-DRB3 genes from six homozygous cell lines (two DRw52a-, two DRw52b-, and two DRw52c-positive) and the 21 patients with primary sclerosing cholangitis hybridised with a DRw52a oligonucleotide probe.

and DP alleles, DR-DQ haplotypes (Table I), as well as the DR4 associated cellular specificities (Table II) were very similar in the patients and the controls.

The distribution of HLA class II specificities was not influenced by subgrouping the patients according to disease location (data not shown). Furthermore, no tendency towards an HLA class II association was found for the occurrence of other extraintestinal complications than sclerosing cholangitis.

CROHN'S DISEASE

The frequencies of DR, DQ, and DP- alleles as well as DR-DQ haplotypes were remarkably similar in patients with Crohn's disease and controls, with the exception of an insignificant increase of DRw52c ( $<<0.05 ; p_{c}$, NS) (Table I).

As two independent Japanese studies have shown a significant DR4 association in Crohn's disease ${ }^{23}{ }^{24}$ we found it of interest to investigate the distribution of the DR4 associated cellular specificities by PCR-SSO typing ${ }^{14}$ in the Swedish patients. However, no deviation in the distribution of these specificities were observed (Table II).

The distributions of HLA class II specificities were similar in patients with disease localised to the small bowel, to the colon, or with ileocolic Crohn's disease, except an insignificant increase of the DRw15, DQw6, Dw2 haplotype in patients with Crohn's disease confined to the colon $\left(p<0.01 ; p_{c}, N S\right)$ and an insignificant decrease of the same haplotype in patients with ileocolic Crohn's disease $\left(p<0.05 ; p_{c}, N S\right)$. Furthermore, no tendency towards an HLA class II association was found for the occurrence of extraintestinal manifestations. However, the number of investigated patients with extraintestinal complications was too small to allow any valid conclusions.

\section{Discussion}

\section{PRIMARY SCLEROSING CHOLANGITIS}

In agreement with three previous studies, ${ }^{122} 25$ an increase of DRw17, a recently introduced subdivision of the DR3 specificity, was observed in the Swedish patients with sclerosing cholangitis (Table III). However, in our group of patients 
TABLE III Summary of $H L A-D R 3(w 17)^{\star}$ studies in patients with primary sclerosing cholangitis

\begin{tabular}{lllllll}
\hline No of patients & No of controls & Ethnic group & Typing method & Finding & $p$ & Reference \\
\hline 20 & NG & Norwegians & Serology & Pos DR3 association & $<0 \cdot 001$ & 25 \\
29 & 1546 & White & Serology & Pos DRw17^association & $<0 \cdot 01$ & 1 \\
81 & 100 & European whites & Serology & Pos DR3 association & $<0 \cdot 0005$ & 22 \\
21 & 250 & Swedish & RFLP & DRw17^ overrepresentation & $<0 \cdot 06$ & present study \\
\hline
\end{tabular}

* DRw17 is the DR3 'split' seen in whites. NG= not given.

the increase failed to reach statistical significance $(\mathrm{p}<0.06)$, which probably represents a statistical type II error.

In our small series of patients, we could not confirm the recently described DR2 association in DR3 negative patients with primary sclerosing cholangitis. ${ }^{22}$

Why could we not confirm the strong DRw52a association in primary sclerosing cholangitis described in Californian patients?' In the present investigation the DRw52a specificity was determined by a genomic typing technique which directly identifies this allele. ${ }^{13}$ In the previous study, the DRw52a specificity was assigned by indirect serological criteria - that is reaction with DRw52 antiserum in the presence of either DR3 or DRw6. If we had used the same criteria, deduced from TaqI DRB-DQA-DQB RFLP analysis, $71 \%$ of the patients compared with $48 \%$ of the controls would have been assigned the DRw52a specificity $\left(\mathrm{p}<0.05 ; \mathrm{p}_{\mathrm{c}}, \mathrm{NS}\right)$, which shows that the different results may be partly attributable to ethnic differences. The indirect serological criteria will, however, lead to an overestimation of the DRw52a specificity in white populations as shown previously ${ }^{12}$ and in Table IV. Ninety six per cent of DRw 17 positive Swedish haplotypes $(n=45)$ carried the DRw52a specificity. However, only $31 \%$ of DRw6 haplotypes $(n=94)$ were DRw52a positive. The distribution of DRw52 alleles in DR3 and DRw6 positive white Americans may well differ from that observed in Swedes (Table IV) and Swiss. ${ }^{12}$ Retyping the Californian patients with a genomic typing technique directly identifying the DRw52a specificity would settle the issue. If a DRw52a association was verified in these patients, it would be of interest to calculate whether this association was secondary to linkage disequilibrium with the $\mathrm{Al}, \mathrm{B} 8, \mathrm{Cw} 7$, DRw17,DQw2,DRw52a haplotype. In our group of patients linkage calculations were inconclusive.

TABLE IV Distribution(\%) of DRw52a, DRw52b, and DRw52c alleles ${ }^{\star}$ on 189 DRw52 positive haplotypes from randomly selected healthy controls

\begin{tabular}{lcccc}
\hline $\begin{array}{l}D R-D Q \\
\text { haplotype }\end{array}$ & $N o$ & $D R w 52 a$ & $D R w 52 b$ & $D R w 52 c$ \\
\hline w11,w7 & 35 & 0 & 100 & 0 \\
w12,w7 & 15 & 0 & 100 & 0 \\
w13†, w6 & 74 & 34 & 28 & 38 \\
w13†,w7 & 4 & 100 & 0 & 0 \\
w14†, w5 & 16 & 0 & 100 & 0 \\
w17, w2 & 45 & 96 & 4 & 0
\end{tabular}

* DRw52 alleles were inferred from TaqI DRB-DQA-DQB RFLP analysis. In nine DRw52 positive homozygous cell lines of the 10th International Histocompatibility Workshop and 60 individuals representing the 10 white DRw52 positive TaqI DRBDQA-DQB haplotypes, DRw52 typing was performed by hybridising PCR amplified DRB3 genes with oligonucleotide probes. ${ }^{13}$ The two methods gave completely concordant results. $t$ DRw 13 and DRw14 are subdivisions of the DRw6 specificity.
In analogy to the associations with specific amino acids of the HLA class II molecules observed in insulin dependent diabetes mellitus ${ }^{2}$ and selective immunoglobulin A deficiency, ${ }^{+}$it was suggested by Prochazka et al that the amino $\operatorname{acid}(s)$ at position(s) $26,38,57$, or 60 of the DRw52a $\beta$ chain, in their report claimed to be unique for this allele, might determine disease susceptibility. ' However as analysis of published sequence data ${ }^{26}$ shows that none of the implicated amino acid positions is unique for the DRw52a allele, the susceptibility to primary sclerosing cholangitis cannot be related to specific amino acid positions of the DRw52a $\beta$ chain.

\section{ULCERATIVE COLITIS}

Immunogenetic data in white patients with ulcerative colitis are briefly summarised below: (i) no increased concordance rate in monozygotic twins'; (ii) analysis of pooled HLA class I data showed weak associations with HLA-B27 and $-\mathrm{Bw} 35$ in white patients. ${ }^{27}$ However, the increase of B27 might be due to the increased occurrence of ankylosing spondylitis, strongly associated with $\mathrm{B} 27,{ }^{56}$ in patients with ulcerative colitis; (iii) no significant HLA class II association $^{25} 2829$ (and present study); (iv) no association with $\mathrm{T}$ cell receptor constant region $\mathrm{RFLPs}^{30}$; and (v) no linkage with immunoglobulin heavy chain allotypes. ${ }^{31}$

We conclude that, although genetic factors cannot be excluded, available data do not support a major genetic aetiological component in ulcerative colitis. However, the insignificant increase of the DRw17,DQw2 haplotype ${ }^{\text {"5 }}$ (and present study), strongly associated with several diseases with autoimmune features is worth noting. It is tempting to speculate, that an as yet undefined subset of ulcerative colitis might be HLA associated.

\section{CROHN'S DISEASE}

A brief summary of immunogenetic data in Crohn's disease is given below: (i) increased concordance rate in monozygotic twins'; (ii) analysis of compiled HLA class I data showed a weak positive association with $\mathrm{A} 2$ and a weak negative association with $\mathrm{A} 11$ in white patients ${ }^{27}$; (iii) no HLA class II association in white patients with Crohn's disease (28 293233 and present study), which is in contrast to the findings in Japanese patients $^{2324}$; (iv) no evidence for linkage with the HLA region in segregation analysis ${ }^{3+35}$; (v) no association with $\mathrm{T}$ cell receptor constant region RFLPs $^{30}$; and (vi) no association or linkage with immunoglobulin heavy chain allotypes. ${ }^{31}$

In conclusion, the data supporting a genetically influenced susceptibility are stronger in 
Crohn's disease than in ulcerative colitis. In Japanese patients a DR4 association has been reproducibly observed. However, family data linking disease susceptibility to the HLA-DR region in the Japanese have not been reported. In whites no strong associations or linkage with any of the major polymorphic components of the immune system - that is, HLA genes, $T$ cell receptor genes, or immunoglobulin genes - have been identified.

This work was presented in part at the 5th European Histocompatibility Conference, 20-22 March 1991, Leiden, The Netherlands.

This study was supported by grants from the Swedish Medica Research Council (grants No 00793 and 08890) and the Swedish Society of Medicine.

1 Prochazka EJ, Terasaki PI, Sik Park M, Goldstein LI, Busuttil RW. Association of primary sclerosing cholangitis with HLA-DRw52a. N Engl F Med 1990; 322: 1842-4.

2 Todd JA, Bell JI, McDevitt HO. HLA-DQ to susceptibility and resistance to insulin-dependent diato susceptibility and resistance to insulin-d
betes mellitus. Nature 1987; 329: 599-604.

3 Gregersen PK, Silver J, Winchester RJ. The shared epitope hypothesis. An approach to understanding the molecular hypothesis. An approach to understanding the molecular genetics of susceptibility to

4 Olerup O, Smith CIE, Hammarström L. Different amino acids at position 57 of the HLA-DQ $\beta$ chain associated with susceptibility and resistance to IgA deficiency. Nature 1990 347: 289-90

5 Schlosstein L, Terasaki PI, Bluestone R, Pearson CM. High association of an HL-A antigen, W27, with ankylosing spondylitis. N Engl F Med 1973; 288: 704-6.

6 Brewerton DA, Caffrey M, Hart FD, James DCO, Nicholls A Sturrock RD. Ankylosing spondylitis and HL-A 27. Lancet 1973; i: $904-7$.

7 Juji T, Satake M, Honda Y, Doi Y. HLA antigens in Japanese patients with narcolepsy. Tissue Antigens 1984; 24: 316-9.
Langdon N, Welsh KI, Van Dam M, Vaughan RW, Parkes D. angdon N, Welsh KI, Van Dam M, Vaughan RW, Parkes
Genetic markers in narcolepsy. Lancet 1984; 2: 1178-80.

9 Tysk C, Lindberg E, Järnerot G, Flodérus-Myrhed B. Ulcerative colitis and Crohn's disease in an unselected population of monozygotic and dizygotic twins. A study of heritability and the influence of smoking. Gut 1988; 29: 990-6.

10 Carlsson B, Wallin J, Böhme J, Möller E. HLA-DR-DQ haplotypes defined by restriction fragment length analysis correlation to serology. Hum Immunol 1987; 20: 95-113.

11 Bidwell JL. DNA-RFLP-analysis and genotyping of HLADR and $-D Q$ antigens. Immunol Today 1988; 9: 18-23.

12 Tiercy J-M, Gorski J, Jeannet M, Mach B. Identification and distribution of three serologically undetected alleles of HLA-DR by oligonucleotide-DNA typing analysis. Proc HLA-DR by oligonucleotide-DNA typin
Natl Acad Sci USA 1988; 85: 198-202.

13 Fernandez-Vina M, Shumway W, Stastny P. DNA typing for class II HLA antigens with allele-specific or group-specific amplification. II. Typing for alleles of the DRw52-associated group. Hum Immunol 1990; 28: 51-64.

14 Lanchbury JSS, Hall MA, Welsh KI, Panayi GS. Sequence analysis of the HLA-DR4B1 subtypes: additional firs domain variability is detected by oligonucleotide hybridization and nucleotide sequencing. Hum Immunol 1990; 27 : $136-44$
15 Weisner RH, La Russo NF. Clinicopathologic features of the syndrome of primary sclerosing cholangitis. Gastroenterology 1980; 74: 200-6.

16 Chapman RWG, Arborgh BA, Rhodes JM, Summerfield JA, Dick R, Scheuer RJ, et al. Primary sclerosing cholangitis: A review of its clinical features, cholangiography and hepatic histology. Gut 1980; 21: 870-7.

17 Evans JG, Acheson ED. An epidemiological study of ulcerative colitis and regional enteritis in the Oxford area. $G u$ 1965; 6: 311-24.

18 Farmer RG, Mawic WA, Turnbull RB. Clinical patterns in Crohn's disease: A statistical study of 6155 cases. Gastroenterology 1975; 68: 627-35.

19 Olerup O, Hillert J, Fredrikson S, et al. Primarily chronic progressive and relapsing/remitting multiple sclerosis: two immunogenetically distinct disease entities. Proc Natl Acad immunogenetically distinct

20 Hyldig-Nielsen JJ, Morling N, Ødum N, et al. Restriction fragment length polymorphism of the HLA-DP subregion and correlation to HLA-DP phenotypes. Proc Natl Acad Sci USA 1987; 84: 1644-8.

21 Rønningen KS, Iwe T, Halstensen TS, Spurkland A, Thorsby E. The amino acid at position 57 of the HLA-DQ $\beta$ chain and susceptibility to develop insulin-dependent diabetes mellitus. Hum Immunol 1989; 26: 215-25.

22 Donaldson PT, Farrant JM, Wilkinson ML, Hayllar K, Portmann BC, Williams R. Dual association of HLA DR2 and DR3 with primary sclerosing cholangitis. Hepatology 1991; 13: 129-33.

23 Fuijta K, Naito S, Okabe N, Yao T. Immunological studies in Crohn's disease. I. Association with HLA systems in the Crohn's disease. I. Association with HLA syst

24 Kobayashi K, Atoh M, Yagita A, et al. Crohn's disease in the Japanese is associated with the HLA-DRw53. Exp Clin Immunogenet 1990; 7: 101-8.

25 Schrumpf E, Fausa O, Førre $\emptyset$, Dobloug JH, Ritland S, Thorsby E. HLA antigens and immunoregulatory $T$ cells in ulcerative colitis associated with hepatobiliary disease. Scand F Gastroenterol 1982; 17: 187-91.

26 Marsh SGE, Bodmer JG. HLA-DRB nucleotide sequences, 1990. Immunogenetics 1990; 31: 141-4.

27 Biemond I, Burnham WR, D'Amaro J, Langman MJS. HLA-A and -B antigens in inflammatory bowel disease. Gut 1986; 27: 934-41.

28 Smolen JS, Gangl A, Polterauer P, Menzel EJ, Mavr WR. HLA antigens in inflammatory bowel disease. GastroHLA antigens in infla

29 Tiwari JL, Terasaki PI. Gastroenterology. In: HLA and disease associations. New York: Springer-Verlag, 1985: 253-8

30 Katakura S, Einarsson K, Hammarström L, Smith CIE. Restriction fragment length polymorphism analysis of $\mathrm{T}$-cell receptor genes in inflammatory bowel disease. Scand $\mathcal{Y}$ Gastroenterol 1989; 24: 381-4.

31 Gudjonsson H, Schanfield MS, Albertini RJ, McAuliffe TL Beeken WL, Krawitt EL. Association and linkage studies of immunoglobulin heavy chain allotypes in inflammatory bowel disease. Tissue Antigens 1988; 31: 243-9.

32 Pena AS, Biemond I, Kuiper G, et al. HLA antigen distribution and HLA haplotype segregation in Crohn's disease. bution and HLA haplotype seg

33 Modena V, Amaroso A, Frattasio C, et al. HLA antigens and clinical manifestations in Crohn's disease. Clin Exp Rheumatol 1988; 6: 221-5.

34 Achord JL, Gunn CH, Jackson JF. Regional enteritis and HLA concordance in multiple siblings. Dig Dis Sci 1982; 27: $330-2$

35 Colombel JF, Guillemot F, van Gossum A, et al. Familia Crohn's disease in multiple siblings: no linkage to the HLA system. Gastroenterol Clin Biol 1989; 13: 676-8. 